\title{
Feasibility Study on Redox Mediator-Stimulating Bioenergy Extraction Using Edible Flora for Sustainable Applications
}

\author{
Jia-Hui Liao, Chung-Chuan Hsueh, Bor-Yann Chen* \\ Department of Chemical and Materials Engineering, National I-Lan University, I-Lan, Taiwan \\ Email address: \\ boryannchen@yahoo.com.tw (Bor-Yann Chen), lisa22684047@gmail.com (Jia-hui Liao), cchsueh88@gmail.com (Chung-Chuan Hsueh) \\ ${ }^{*}$ Corresponding author
}

To cite this article:

Jia-hui Liao, Chung-Chuan Hsueh, Bor-Yann Chen. Feasibility Study on Redox Mediator-Stimulating Bioenergy Extraction Using Edible Flora for Sustainable Applications. Science Discovery. Vol. 6, No. 1, 2018, pp. 19-26. doi: 10.11648/j.sd.20180601.14

Received: March 4, 2018; Accepted: March 30, 2018; Published: May 23, 2018

\begin{abstract}
This first-attempt study used extracts of appropriate antioxidant abundant Camellia and non-Camellia tea and medicinal herbs as model ESs to stably intensify bioelectricity generation performance in microbial fuel cells (MFCs). As electron shuttles (ESs) could stimulate electron transport phenomena by significant reduction of electron transfer resistance, the efficiency of power generation for energy extraction in microbial fuel cells (MFCs) could be appreicably augmented. Using environmentally friendly natural bioresource as green source of ESs is the most promising to sustainable practicability. As comparison of power-density profiles indicated, supplement of Camellia tea extracts seemed to be the most appropriate, then followed non-Camellia Chrysanthemum tea and medicinal herbs. Antioxidant activities, total phenolic contents and power stimulating activities were all electrochemically associated. In particular, the extract of unfermented Camellia tea (i.e., green tea) was the most promising ESs to augment bioenergy extraction compared to other refreshing medicinal herb extracts for biorefinery applications.
\end{abstract}

Keywords: Medicinal Herbs, Antioxidant, Bioelectrochemistry, Electron Shuttle, Bioenergy Extraction

\section{可食用性植物電子梭萃液促進生物能源精煉之永續性應用可行性 研究}

\author{
廖家輝，薛仲娟，陳博彥* \\ 化學工程與材料工程學系, 國立宜蘭大學, 宜蘭市, 台灣
}

\section{邮箱}

lisa22684047@gmail.com（廖家輝）, cchsueh88@gmail.com（薛仲娟）, boryannchen@yahoo.com.tw（陳博彥）

\begin{abstract}
摘要: 本研究首次嘗試使用富含豐富抗氧化劑的茶葉、花茶和中草藥提取物作為評估具有典型電子梭(ESs)之應用可行 性, 以達到穩定增強微生物燃料電池（MFCs）生物產電之效能。並由電子梭（ES）添加以有效降低電子傳遞阻抑來 刺激電子傳輸, 因此MFC中能量獲取發電效率亦可被顯著增強。由於以環保天然生物資源作為綠色 $\mathrm{ES}$ 生物資源具有永 續發展性。由功率密度趨勢曲線更指出, 綠茶提取物的添加為最佳者, 然後則是菊花茶和草藥。研究結果更證明抗氧 化活性, 總酚含量和能量刺激活性皆是電化學上彼此息息相關的。總而言之, 與其他提神相關藥用草藥提取物相比, 未發酵綠茶的提取物應是增強生物能量提取天然物中最有前途之ES, 更有利於生物能源精煉之永續開發應用上。
\end{abstract}

關鍵詞: 中草藥材, 抗氧化物, 生物電化學, 電子梭, 生物能量提取 


\section{1. 引言}

依據聯合國調查報告, 可再生能源於未來三四十年內將 成為全球的一大能源主軸。特別是生質能源更是作為可持續 發展最佳的可再生能源選項。其中尤其是微生物燃料電池 (MFC)是一種生物電化學系統, 可通過使用具高電化學活性 細菌自有機物氧化來回收獲得電流。另外, 氧化還原中介體 （RM）之介入亦可輔助MFC效能, 更是最節能且經濟效益 上更具前瞻性的選項, 因為補充電子梭(ES)將提高有效電子 轉移(ET)效率, 並顯著降低產電的內部傳輸阻抑 $[1]$ 。其中ES 或RM (例如: 兒茶酚, 核黃素) 更可重覆被可逆地氧化和 還原以中介電子傳遞來作為用於能量提取的電化學活性催 化劑。總而言之 隨著ES的補充 電子傳遞(ET)能力的提高, 亦可同時提高電化學調控生物分解的污染物降解及生物產 電效率。然而添加處理的輔助污染物ES, 若是經由化學反應 後產生(例如:亞甲基藍, 中性紅及紡織染料的脱色代謝物) 來提高污染物降解速率, 顯然不具環境生態之永續應用性。 若添加ES來提高MFC的運行效率是無以避免的, 那麼添加 自然存在的ES將成為綠色永續上最優先選擇, 以盡可能减少 對生態環境衝擊。事實上, 對於ES的化學結構而言, 當苯環 上存在吸電子基團（例如: 羥基 (- $\mathrm{OH}$ ) 取代基) 時, 此類 化學物質將強烈表現出電化學穩定的電子穿梭特性, 以刺激 電子傳遞 $[2,3]$ 。亦即是, 在多酚類化學結構存在的情況下, 可能因具有可能的ES電子中介穿梭特性, 可以有效刺激 $\mathrm{MFC}$ 的電子傳遞效率。因此, 使用多酚（即含多重-OH取代 基化合物）的藥用植物草藥和可食用植物（例如：普通茶和 花草茶) 作為ES, 似乎更具生物電化學上之相容可行性。此 外, 藥用植物Lonicera japonica (Jīnyín-huā) 和 Syzygium aromaticum (Dīng-xiāng) [4, 5]含有大量的多酚類和類黃酮 抗氧化劑 $[6,7]$ 。因此, 多酚類豐富的天然生物的抗氧化能力 和ES能力, 亦被認為是誘導型電化學特性, 可被外在條件下 的生物產電激發操縱。換言之, 若能夠有效表達ES活性, 那 麼多酚類化合物的存在, 亦可以協同促進MFC中ET刺激的 電化學交互作用。再者, 茶葉的成分兒茶素在適當的條件下, 可起到抗氧化物及ES的雙重作用[4]。儘管Chen和Hsueh[8] 提出以富含多酚的可食用生物資源來作為生物能源應用 (例 如:MFC, 電發酵) 的ES (例如: 類黃酮抗氧化物作為可能 的ES）的合理原因, 但實際上自多種天然生物資源, 以提取 具有電化學活化物仍有待深入探究。依據本研究結果指出, 針對測試樣品的比較評估中發現, 普通茶葉 (例如: 綠茶, 烏龍茶, 普洱茶和紅茶) 的提取物對於刺激MFC中的電子傳 輸現象是最為合適的。後續研究將破解是否可取自一些重要 的天然化學物質作為主要效應物, 並由幾種電化學活性物質 的協同交互作用來有效提高MFC中的產電效能 以利應用於 生物能源, 甚至於中草藥藥性及藥效的相關領域中。

\section{2. 材料與方法}

\section{1. 常見可食用天然草本植物萃取液}

本研究取定普通茶-Camellia sinensis (L.) Kuntze (綠 茶), Oolong tea(烏龍茶), Camelliaboreali yunnanica(滇紅),
Camellia assamica (Mast.) Chang(普耳) 及花草茶 Coreopsis tinctoria Nutt. (崑崙雪菊), Chrysanthemum (菊 花) and Bellis perennis (雛菊) 及中草藥-Lonicera japonica (金銀花), Syzygium aromaticum (丁香), Citrus reticulate (陳皮)為目標比較待測樣品, 首先以新鮮 $2.5 \mathrm{~g}$, 浸泡於 $50 \mathrm{~mL}$ 的 $50 \%$ 乙醇溶液中 (酒萃), 在攝氏 $65^{\circ} \mathrm{C}$ 下迴 流萃取 2 小時, 再減壓濃縮 15 分鐘, 進行抽氣過濾, 取其 萃液, 最後再加適量去離子水, 將其定量至 $50 \mathrm{~mL}$, 以利 後續評估分析。

\section{2. 循環伏安法測試}

循環伏安測是採三極標準法, 工作電極, 反電極和參 考電極分別為玻碳電極 $\left(0.07 \mathrm{~cm}^{2}\right)$, 鉑電極 $\left(6.08 \mathrm{~cm}^{2}\right)$ 和充滿飽和 $\mathrm{KCl}$ (水溶液) 的 $\mathrm{Ag} / \mathrm{AgCl}$ 電極。研究前, 玻 璃碳電極 (GCE, ID = 3mm;型號CHI104, CH Instruments Inc., USA）用 $0.05 \mu \mathrm{m}$ 氧化鋁抛光劑抛光, 將中草藥汁液 以氮氣曝氣去氧 15 分鐘後, 再使用儀器 electrochemical work station(Jiehan 5600, Taiwan), 掃描範圍+1.5V到-1.5V, 速率為 $10 \mathrm{mV} \cdot \mathrm{s}^{-1}$ 。由於中草藥本乃多元複雜之混合物, 因 此取定六次掃描觀察在於決定是否具有穩定氧化還原峰, 再將具有此特性之樣品, 再進行循環伏安掃描 100 圈, 以 觀察其圖譜之可逆性穩定變化趨勢分析曲線。

\section{3. 總酚含量測試}

將中草藥萃液量取 $0.25 \mathrm{~mL}$ 與 $0.25 \mathrm{~mL}$ Folin \& Ciocalteu's phenol reagent, $0.5 \mathrm{~mL}$ 飽和 $\mathrm{Na}_{2} \mathrm{CO}_{3}$ 溶液和 $4 \mathrm{~mL}$ 雙蒸飹水混合, 以分光光度計在吸收波長 $\lambda=725 \mathrm{~nm}$ 下測試 並以 Gallic acid (GA)當作標準品作較正曲線, 得校正方程 式 $\mathrm{OD}_{\mathrm{GA}}=3.6748 \mathrm{C}_{\mathrm{GA}}-0.0475 ; \mathrm{r}^{2}=0.9993, \mathrm{OD}_{\mathrm{GA}}$ 是樣品吸光 度, $\mathrm{C}_{\mathrm{GA}}$ 是相當於 $\mathrm{GA}$ 濃度 $\left(\mathrm{g} \mathrm{L}^{-1}\right)$ 。

\subsection{DPPH抗氧化測試}

DPPH清除測試，使用2,2-二苯基-2-苦基肼（DPPH•; $\mathrm{C}_{18} \mathrm{H}_{12} \mathrm{~N}_{6} \mathrm{O}_{5}$ •) 自由基作為評估抗氧化活性的標準。對DPPH 自由基清除率的自由基清除能力由下列方程式判定

DPPH 自由基清除 $=\left(1-\quad\left(\mathrm{Abs}_{\text {sample }}-\mathrm{Abs}_{\text {blank }}\right)\right)$ $\mathrm{Abs}_{\text {control }}$ ) $\times 100 \%$ 其中 $A \mathrm{Abs}_{\mathrm{sample}}$ 是 30 分鐘後DPPH與樣品 (或 標準品）之間反應的吸光度, $\mathrm{Abs}_{\text {blank }}$ 是空白值 (即 $2 \mathrm{~mL}$ ethanol溶劑和 $1 \mathrm{~mL}$ 樣品或標準溶液) 的吸光度, $\mathrm{Abs}_{\text {control }}$ 是 對照 ( $1 \mathrm{~mL}$ DPPH溶液和 $2 \mathrm{~mL}$ 溶劑) 的吸光度。正如 Oliverira等人[9]指出, 以 $2 \mathrm{~mL}$ 不同稀釋度的 $1 \mathrm{mM} \mathrm{DPPH}$ (溶 於 $95 \%$ 乙醇) 瓶與不同濃度的 $1 \mathrm{~mL}$ 測試藥草或茶提取物混 合, 在室溫下進行反應 30 分鐘。然後再通過 $515 \mathrm{~nm}$ 的分光 光度分析追蹤。

\section{5. 微生物燃料電池製備}

針對電子梭研究, 本研究使用空氣陰極單槽式微生物 燃料電池 (聚甲基烯酸甲酯 (Poly(methyl methacrylate), PMMA) (single-chamber MFCs, SC-MFCs), 來作為微生物 燃料電池。首先取定長 $95 \mathrm{~mm}$, 厚 $3 \mathrm{~mm}$, 內徑 $54 \mathrm{~mm}$ 圓 管一支, 一端作為陽極閉口端, 另一開端作為空氣陰極開 
口, 以此段槽體做為微生物反應槽。陽極生物反應槽之工 作體積為 $231.3 \mathrm{~mL}$ 邊緣以矽利康 (silicone) 固定玻璃管, 並在槽正中央鑽出直徑 $11 \mathrm{~mm}$ 的孔洞, 以作為後續可置 參考電極與輔助電極之位置, 利於電化學分析儀對電池測 量。構造上，圓管兩端的陽極閉口端與空氣陰極開口端分 別接上直徑 $54 \mathrm{~mm}$ 圓洞的壓克力圓盤, 距圓盤中心 $42 \mathrm{~mm}$ 處 鑽出直徑 $8 \mathrm{~mm}$ 之孔洞六個，並製作相同規格的熱片以防 止漏液, 熱片及電極碳布 (陽極碳布直徑 $54 \mathrm{~mm}$ 的圓形親 水多孔碳布, 陰極碳布以四氟乙烯塗布, 其直徑 $54 \mathrm{~mm}$ 的 圓形疏水多孔碳布, 其一端延伸 $60 \mathrm{~mm}$ 的碳布) 放於圓管 與圓盤間並以矽利康 (silicone) 黏合, 再以螺栓將圓管與 圓盤緊連。

微生物燃料電池之培養液為培養基 LB (Luria-Bertani medium), 組成之成分為 $10 \mathrm{~g} \mathrm{~L}^{-1}$ 的胰蛋白 酶(tryptone)， $5 \mathrm{~g} \mathrm{~L}^{-1}$ 的酵母提取物 (yeast extract) 及 $10 \mathrm{~g}$ $\mathrm{L}^{-1}$ 的氯化鈉 $(\mathrm{NaCl})$ 所組成, 培飬基本身 $\mathrm{pH}$ 值微調確定 在 $7.0 \pm 0.2$ 之間; 培養基主要提供作為菌體生長及電池電 流生產所需之能量。

MFCs所殖種之菌株希瓦氏菌(Shewanella haliotis)乃來 自於過去生化工程研究室自行篩選出來具有生物脫色與產 電菌株, 並在首次殖種時於 $30^{\circ} \mathrm{C} 、 125 \mathrm{rpm}$ 條件下殖入菌液 $1 \%(\mathrm{v} / \mathrm{v})$ 並在含有 $50 \mathrm{ml}$ 的 LB培養基進行前培養 $12 \mathrm{hr}$, 並取其 菌液 $2.2 \mathrm{ml}$ 殖入含有 $220 \mathrm{ml} \mathrm{LB}$ 培養基微生物燃料電池槽體內, MFCs之工作環境為 $25^{\circ} \mathrm{C}$, 為提供有效能量營養基質, 並以 $48 \mathrm{hr}$ 為週期為脈衝注入 $5 \mathrm{~mL}$ 高溫殺菌濃縮新鮮基質 8.8 倍濃度 LB 培養液使MFCs內維持 0.2 倍LB基質。

\subsection{MFC電化學測試}

(a)電化學阻抗譜（EIS）(日本HIOKI 3522-50) 測量 是在幅度為 $10 \mathrm{mV}$ 的穩態開路電勢下進行的。頻率範圍是 $104 \sim 5 \times 10-2 \mathrm{~Hz}$ 收集的數據使用奈奎斯特圖的軟件 (Zview 2.6b, Jiehan Tech Corp.）進行分析。以二極法MFCs陽極 為工作電極, 陰極為參考電極與輔助電極, 在穩定電壓, (a)電化學阻抗譜（EIS）（日本HIOKI 3522-50）測量是在 幅度為 $10 \mathrm{mV}$ 的穩態開路電勢下進行的。頻率範圍是 $10^{4 \sim 5} \times 10^{-2} \mathrm{~Hz}$ 。收集的數據使用奈奎斯特圖的軟件（Zview 2.6b, Jiehan Tech Corp.）進行分析。以二極法MFCs陽極 為工作電極, 陰極為參考電極與輔助電極, 在穩定電壓, 擾動振幅為 $10.0 \mathrm{mV}$, 頻率範圍為 $10^{4 \sim 5} \times 10^{-2} \mathrm{~Hz}$ 阻抗圖 (EIS 曲線）與 $x$ 軸的截距（阻抗, $Z_{\mathrm{re}}$ ), 可作為電解質電阻 (electrolyte resistance, $\mathrm{R}_{\mathrm{ele}}$ ) ; 而阻抗圖中的曲線在 $x$ 軸交 點後的曲線投影長度是反應動力電阻（kinetic resistance） 與質傳電阻（擴散電阻）之和 $\left(\mathrm{R}_{\mathrm{kin}}+\mathrm{R}_{\mathrm{diff}}\right.$ ) 將三者總和值 則為電池內阻 $R_{\text {in }}\left(R_{\text {elec }}+R_{\text {kin }}+R_{\text {diff }}\right)$, 使用奈奎斯特圖軟 件 (Zview 2.6b, Jiehan Tech) 收集數據和分析估算電化 學特[10]。

(b)產電測量：使用數據採集系統（DAS 5020; Jiehan Tech Corp.）通過外部電阻 $\mathrm{R}_{\text {out }}=1 \mathrm{~K} \Omega$ 自動測量電池電壓 （每分鐘設定一個數據點）。請注意, 為了與之前的結果 進行比較, 故意使用較高的電阻（1000歐姆）。使用線性 掃描伏安法 $(\mathrm{LSV})$ 測量 $\mathrm{P}=(\mathrm{V} \times \mathrm{C}) / \mathrm{A}$ 和 $\mathrm{I}=\mathrm{C} / \mathrm{A}$ 來確定 $\mathrm{MFC}$ 的功率密度 $(\mathrm{P})$ 和電流密度 $(\mathrm{I})$, 並且使用萬用表 $\mathrm{V}$ 和 $\mathrm{C}$ 分別
表示電壓和電流）。所有的 $\mathrm{MFC}$ 在 $25^{\circ} \mathrm{C}$ 下在無膜單室模型 中操作。並將天然植物萃液添加 $5 \%(\mathrm{~V} / \mathrm{V})$ 進入 $\mathrm{MFC}$ 中以作 上述之測試。

\section{3. 結果與討論}

\section{1. 模式天然可食用植物取液電化學評估}

如文獻[11]所述，產電細菌的能力通過至少三種機制 顯著影響MFC生物發電的性能: 電子穿梭中介體 (例如: phenazine, quinones）, 膜結合的氧化還原蛋白（例如細胞 色素等移動電子載體），和導電菌毛（或納米導線）（例 如: Shewanella oneidensis）。若電池模組、菌體等外在因 素因條件皆已設定皆不列入考慮, 可影響產電至為關鍵的 因素將只剩外源性之電子傳遞介體(ES)。顯然，尋求可持 續發展的天然存在或生物ESs作為輔助刺激生物產電將是 首要考慮。先前研究指出茶葉與中草藥具有優異的抗氧化 活性, 尤其是茶葉萃液添加到MFC中, 發現其具有顯著之 刺激電子梭能力, 各種天然植物可能皆具有促進電子梭電 子傳遞之能力, 所以將常見天然植物分成-普通茶、花草 茶、中草藥三類別以分別進行測試評估(如圖 1 及表 1 所 示)。

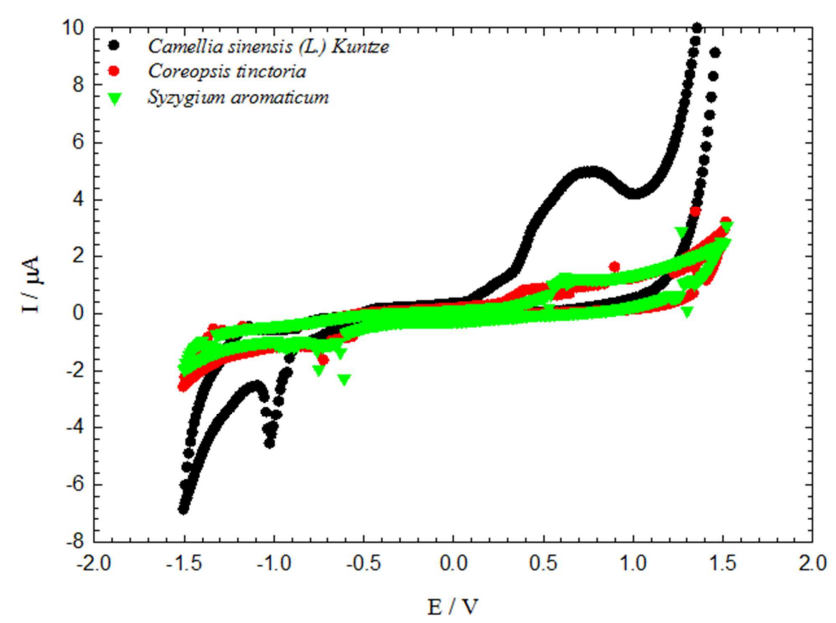

圖1 三類中具最佳電化學活性之植物萃液(普通茶-Camellia sinensis (L.) Kuntze,花草茶-Coreopsis tinctoria Nutt.,中草藥-Syzygium aromaticum)的 循環伏安曲比較圖。

表1 普通茶和花草茶及中草藥的循環伏安分佈圖面積比較。

\begin{tabular}{ll}
\hline Test sample & Area* $(\mathbf{V} \cdot \boldsymbol{\mu} \mathbf{A})$ \\
\hline Camellia sinensis $($ L.) Kuntze & 6.73 \\
Coreopsis tinctoria & 2.10 \\
Syzygium aromaticum & 1.92 \\
\hline
\end{tabular}

*Area $=\int_{V_{L}}^{V_{H}}\left(i_{h}-i_{l}\right) d V$

其中 $\mathrm{V}_{\mathrm{H}}, \mathrm{V}_{\mathrm{L}}$ 分別表示在 $+1.5 \mathrm{~V}$ 和 $-1.5 \mathrm{~V}$ 處的 CV掃描的電壓; $\mathrm{i}_{\mathrm{h}}, \mathrm{i}_{1}$ 分別在特 定的掃描電壓下呈現最高和最低的電流值

圖1及表 1 即顯示三種典型天然植物之萃液活性次序 分別為-茶 $>$ 花草茶 $\approx$ 中草藥, 尤其是茶的 CV 面積是其他兩 種植物萃葉的兩倍以上, 由此可以推斷茶類植物萃液可能 具有最佳電子傳遞處盡之電子梭活性。事實上, 長久以來 
綠茶就常被用來作為中草藥材之抗氧化活性比較之標準 品, 因為綠茶乃最佳抗氧化活性天然物。[明]朱權く茶譜 〉更指明茶有伏睡魔的功用, 更是古人在生物電化學活性 上, 有效促進能量傳遞相關之最佳間接臨床活性佐證。

\section{2. 總酚類物質濃度 (TPC) 分析}

再者, 如表2所示, 普通茶, 花草茶(菊花茶)和中草藥的 總酚含量TPC (mg GAE / g EW) 排序依次為綠茶 (216.25)> 烏龍茶 (164.33) >滇紅 (116.61) >普耳 (85.68) > 崦崙雪 菊 $(76.55)>$ 菊花 $(35.75)>$ 雛菊 $(32.35)>丁$ 香 $(23.88)>$ 金銀花 (15.15) >陳皮（12.47）。本研究萃液根據中國明代 李時珍的“本草綱目”, 先前即已有20多種提神降火之藥材其 電子梭與電化學活性被研究過[4], 文獻[12, 13]亦提及菊花
茶類（例如C. morifolium Ramat）含有特定的菊科植物作為 功能材料。藉由富含多酚類和黄酮類成分下, 菊花茶中, 崑 崙雪菊(Coreopsis tinctoria Nutt.)乃最具開發價值的菊花茶, 不僅具有抗氧化活性, 而且具有多種藥理功能 $[12,14]$ 。另外, 菊花植物茶葉中含有大量的多酚和黃酮類化合物。實際上, 酚類化合物（例如: 並基取代基豐富的化合物 - 兒茶素, 蘆丁, 異檞皮苷和䚞皮苷) 的此類主要成分亦極可能與其電 子穿梭活性有關。最有趣的是從TPC含量來看雪菊 $(C$. tinctoria Nutt) (76.55 mg GAE / g EW) 低於發酵茶（例如: 烏龍茶（164.33 mg GAE / g EW）, 紅茶 (85-116 mg GAE/ g EW）（表3）[15], 但C. tinctoria Nutt卻擁有幾乎相同的功 率刺激和電子轉移能力(3.2節所述), 此點更顯現出雪菊可能 具更高經濟開發價值。

表2（a）普通茶，（b）花草茶和（c）中草藥提取物中總酚含量（TPC）的比較。

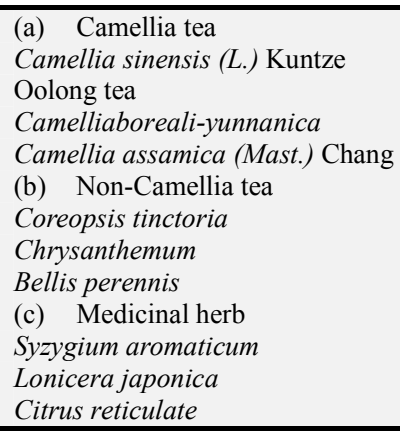

\section{3. 抗氧化活性V.S生物電子介導能力}

如上所述, CV掃描圖譜中茶葉提取物具最大的 CV面 積與更豐富的TPC, 極可能擁有最佳的抗氧化/電子梭活性。 為了驗證此點, 更依據毒理學的劑量反應分析評價對的抗 氧化活性進行排名。由於先前研究 $[4,5]$ 提出, 測試化學物 種的DPPH自由基清除能力和電子穿梭活性可能皆是電化 學上相關聯的。也就是說, 對於富含多酚的植物物種 (例 如:中藥草、普通茶和花草茶提取物) 來說, DPPH自由基 清除活性極可能與ESs的氧化還原中介能力平行, 以刺激 MFC中的生物產電。如圖3所示, 提出了不同植物 DPPH 自由基清除能力的排序。待測抗氧化物的能力亦可通過有 效濃度 $\left(\mathrm{EC}_{\mathrm{x}}\right)$ 來表示, 在 30 分鐘內有 $1 \% \mathrm{DPPH}$ 去除 $\mathrm{x} \%[16]$ 用於分析 (定義的響應 $\mathrm{P} \%=1$-殘留 $\mathrm{DPPH} / \mathrm{DPPH}_{0}$ ) $\times 100$ )。 $\mathrm{EC}_{0}$ 和 $\mathrm{EC}_{100}$ 可以定義為具有可感測響應 (即 $\left.0^{+} \%\right)$ 的最大 濃度和分別具有 $100 \%$ 響應的最小濃度。對於具有不同抗 氧化能力的不同測試樣品, $\mathrm{EC}_{\mathrm{x}}$ 將具有重要的意義。根據

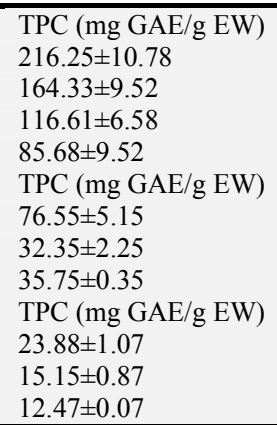

表3 (A) 普通茶(B) 花草茶 (C) 中草藥 提取物DPPH自由基清除活性劑量 - 反應曲線關鍵參數比較表（單位： $\mathrm{g} \mathrm{L}^{-1}$ )。

\begin{tabular}{|c|c|c|c|c|}
\hline (A) Camellia tea & $\mathrm{EC}_{0}$ & $\mathrm{EC}_{20}$ & $\mathrm{EC}_{50}$ & $Y=A+B \log Z$ \\
\hline Camellia sinensis (L.) Kuntze & 0.016 & 0.081 & 0.195 & $Y=6.57+2.21 \log Z$ \\
\hline Oolong tea & 0.061 & 0.195 & 0.363 & $Y=6.37+3.11 \log Z$ \\
\hline Camelliaboreali yunnanica & 0.078 & 0.288 & 0.584 & $Y=5.64+2.74 \log Z$ \\
\hline Camellia assamica (Mast.) Chang & 0.094 & 0.360 & 0.740 & $Y=5.35+2.68 \log Z$ \\
\hline (B) Non-Camellia tea & $\mathrm{EC}_{0}$ & $\mathrm{EC}_{20}$ & $\mathrm{EC}_{50}$ & $Y=A+B \log Z$ \\
\hline Coreopsis tinctoria & 0.00281 & 0.0212 & 0.218 & $Y=5.58+0.856 \log Z$ \\
\hline Chrysanthemum & 0.00059 & 0.0279 & 0.221 & $\mathrm{Y}=5.60+0.962 \log \mathrm{Z}$ \\
\hline Bellis perennis & 0.0112 & 0.176 & 0.773 & $\mathrm{Y}=5.14+1.32 \log \mathrm{Z}$ \\
\hline Syzygium aromaticum & 0.00452 & 0.100 & 0.530 & $Y=5.32+1.16 \log Z$ \\
\hline Lonicera japonica & 0.00237 & 0.107 & 0.835 & $Y=5.07+0.941 \log Z$ \\
\hline Citrus reticulate & 0.300 & 3.323 & 11.594 & $\mathrm{Y}=3.39+1.51 \log \mathrm{Z}$ \\
\hline
\end{tabular}

\begin{tabular}{|c|c|c|c|c|}
\hline (A) Camellia tea & $\mathrm{EC}_{0}$ & $\mathrm{EC}_{20}$ & $\mathrm{EC}_{50}$ & $Y=A+B \log Z$ \\
\hline Camellia sinensis (L.) Kuntze & 0.016 & 0.081 & 0.195 & $Y=6.57+2.21 \log Z$ \\
\hline Oolong tea & 0.061 & 0.195 & 0.363 & $Y=6.37+3.11 \log Z$ \\
\hline Camelliaboreali yunnanica & 0.078 & 0.288 & 0.584 & $Y=5.64+2.74 \log Z$ \\
\hline Camellia assamica (Mast.) Chang & 0.094 & 0.360 & 0.740 & $Y=5.35+2.68 \log Z$ \\
\hline (B) Non-Camellia tea & $\mathrm{EC}_{0}$ & $\mathrm{EC}_{20}$ & $\mathrm{EC}_{50}$ & $Y=A+B \log Z$ \\
\hline Coreopsis tinctoria & 0.00281 & 0.0212 & 0.218 & $Y=5.58+0.856 \log Z$ \\
\hline Chrysanthemum & 0.00059 & 0.0279 & 0.221 & $\mathrm{Y}=5.60+0.962 \log \mathrm{Z}$ \\
\hline Bellis perennis & 0.0112 & 0.176 & 0.773 & $\mathrm{Y}=5.14+1.32 \log \mathrm{Z}$ \\
\hline Syzygium aromaticum & 0.00452 & 0.100 & 0.530 & $Y=5.32+1.16 \log Z$ \\
\hline Lonicera japonica & 0.00237 & 0.107 & 0.835 & $Y=5.07+0.941 \log Z$ \\
\hline Citrus reticulate & 0.300 & 3.323 & 11.594 & $\mathrm{Y}=3.39+1.51 \log \mathrm{Z}$ \\
\hline
\end{tabular}

\begin{tabular}{|c|c|c|c|c|}
\hline (A) Camellia tea & $\mathrm{EC}_{0}$ & $\mathrm{EC}_{20}$ & $\mathrm{EC}_{50}$ & $Y=A+B \log Z$ \\
\hline Camellia sinensis (L.) Kuntze & 0.016 & 0.081 & 0.195 & $Y=6.57+2.21 \log Z$ \\
\hline Oolong tea & 0.061 & 0.195 & 0.363 & $Y=6.37+3.11 \log Z$ \\
\hline Camelliaboreali yunnanica & 0.078 & 0.288 & 0.584 & $Y=5.64+2.74 \log Z$ \\
\hline Camellia assamica (Mast.) Chang & 0.094 & 0.360 & 0.740 & $Y=5.35+2.68 \log Z$ \\
\hline (B) Non-Camellia tea & $\mathrm{EC}_{0}$ & $\mathrm{EC}_{20}$ & $\mathrm{EC}_{50}$ & $Y=A+B \log Z$ \\
\hline Coreopsis tinctoria & 0.00281 & 0.0212 & 0.218 & $Y=5.58+0.856 \log Z$ \\
\hline Chrysanthemum & 0.00059 & 0.0279 & 0.221 & $\mathrm{Y}=5.60+0.962 \log \mathrm{Z}$ \\
\hline Bellis perennis & 0.0112 & 0.176 & 0.773 & $\mathrm{Y}=5.14+1.32 \log \mathrm{Z}$ \\
\hline Syzygium aromaticum & 0.00452 & 0.100 & 0.530 & $Y=5.32+1.16 \log Z$ \\
\hline Lonicera japonica & 0.00237 & 0.107 & 0.835 & $Y=5.07+0.941 \log Z$ \\
\hline Citrus reticulate & 0.300 & 3.323 & 11.594 & $\mathrm{Y}=3.39+1.51 \log \mathrm{Z}$ \\
\hline
\end{tabular}

\begin{tabular}{|c|c|c|c|c|}
\hline (A) Camellia tea & $\mathrm{EC}_{0}$ & $\mathrm{EC}_{20}$ & $\mathrm{EC}_{50}$ & $Y=A+B \log Z$ \\
\hline Camellia sinensis (L.) Kuntze & 0.016 & 0.081 & 0.195 & $Y=6.57+2.21 \log Z$ \\
\hline Oolong tea & 0.061 & 0.195 & 0.363 & $Y=6.37+3.11 \log Z$ \\
\hline Camelliaboreali yunnanica & 0.078 & 0.288 & 0.584 & $Y=5.64+2.74 \log Z$ \\
\hline Camellia assamica (Mast.) Chang & 0.094 & 0.360 & 0.740 & $Y=5.35+2.68 \log Z$ \\
\hline (B) Non-Camellia tea & $\mathrm{EC}_{0}$ & $\mathrm{EC}_{20}$ & $\mathrm{EC}_{50}$ & $Y=A+B \log Z$ \\
\hline Coreopsis tinctoria & 0.00281 & 0.0212 & 0.218 & $Y=5.58+0.856 \log Z$ \\
\hline Chrysanthemum & 0.00059 & 0.0279 & 0.221 & $\mathrm{Y}=5.60+0.962 \log \mathrm{Z}$ \\
\hline Bellis perennis & 0.0112 & 0.176 & 0.773 & $\mathrm{Y}=5.14+1.32 \log \mathrm{Z}$ \\
\hline Syzygium aromaticum & 0.00452 & 0.100 & 0.530 & $Y=5.32+1.16 \log Z$ \\
\hline Lonicera japonica & 0.00237 & 0.107 & 0.835 & $Y=5.07+0.941 \log Z$ \\
\hline Citrus reticulate & 0.300 & 3.323 & 11.594 & $\mathrm{Y}=3.39+1.51 \log \mathrm{Z}$ \\
\hline
\end{tabular}

$\mathrm{EC}_{0}, \mathrm{EC}_{20}$ 和 $\mathrm{EC}_{50}$ (單位: $\mathrm{g} \mathrm{L}^{-1}$ ) 的劑量 - 反應關係 (常 用於毒理學有效效價評估）DPPH自由基清除活性排序依 次為圖 2 和表 3 (a) 至 (c)。此劑量 - 反應評估提供量化 測試物質可引起多大的抗氧化活性的估價。該評估方案定 量評估由不同量的測試物質引起的抗氧化劑活性的類型 和程度。由於 $\mathrm{EC}_{50}$ (半數最大有效濃度) 直接指在參考 $\mathrm{DPPH}_{0}$ 的閾值 $\left(\mathrm{EC}_{0}\right)$ 和最大值 $\left(\mathrm{EC}_{100}\right)$ 之間誘導抗氧化 活性的測試物質的濃度。因此, $\mathrm{EC}_{50}$ 點是劑量 - 反應曲 線的拐點, 顯示受試物質的比較指標如下: (單位: $\mathrm{g} \mathrm{L}^{-1}$ )

$\mathrm{EC}_{50}$ : C. sinensis (L.) Kuntze $(0.195)>C$. tinctoria $(0.218) \sim$ Chrysanthemum $(0.221)>$ Oolong tea $(0.363)>S$. aromaticum $(0.530)>C$. yunnanica $(0.584)>C$. assamica (Mast.) Chang $(0.740)>B$. perennis $(0.773)>L$. japonica $(0.835)>>$ C. reticulate (11.594).

顯然以生物能量的觀點來看, 茶葉確實是最佳電化學 天然物質之首選, 其最低 $\mathrm{EC}_{50}\left(0.195 \mathrm{~g} \mathrm{~L}^{-1}\right)$ 之抗氧化活性更 證明具有極高生物能量運用之價值潛力。 


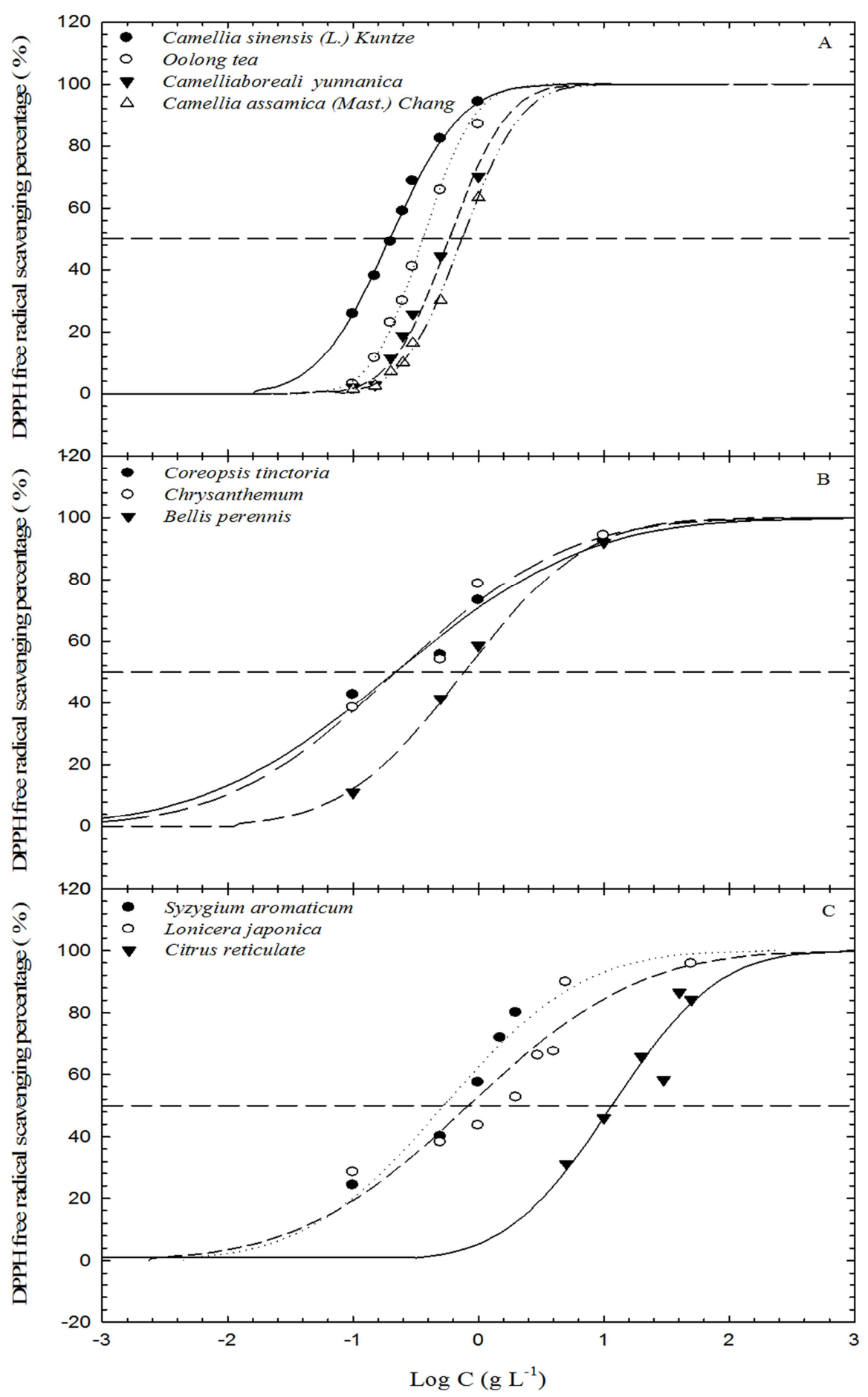

圖2（A) 茶葉，（B）花草茶和（C）中草藥提取物的劑量 - 反應曲線的DPPH自由基清除抗氧化活性的比較圖。

依據劑量反應曲線的probit模型表徵之斜率因子B亦 可定義為測試物質清除“急性”或“慢性”抗氧化活性的自 由基清除能力的範圍有效的指標[17]。當標準劑量響應曲 線的斜率因子 $\mathrm{B}$ 以 1 為標準, 各種茶提取物的曲線所有斜率 因子B均大於 1 , 因此可清楚地表明普通茶提取物具有最佳 的抗氧化/電子梭特性。根據斜率 $\mathrm{B}$, 萃液能力依序遞減排 列如下:

斜率因子B: Oolong tea $(3.11)>C$. yunnanica $(2.74)>$ C. assamica (Mast.) Chang (2.68) $>$ C. sinensis (L.) Kuntze
(2.21) $>C$. reticulate $(1.51)>B$. perennis $(1.32)>S$. aromaticum $(1.16)>$ Chrysanthemum $(0.962)>$ L. japonica $(0.941)>C$. tinctoria $(0.856)$.

茶葉提取物的斜率因子 B值大於1（約2.21-3.11）（例 如:綠茶, 烏龍茶, 普洱茶和紅茶), 顯示自由基清除能 力公範圍較小, 即從閾值劑量 $\left(\mathrm{EC}_{0}\right)$ 到最大效應劑量 $\left(\mathrm{EC}_{100}\right)$ 的能力改變甚大。因此懷疑具有顯著的 $\mathrm{ES}$ 電化 學活性反應亦可能增強MFC中的產電量。若DPPH自由基 清除能力在電化學活性方面確實是MFC中的抗氧化物和 
電子中介物質, 普通茶提取液顯然更合適作為添加劑, 其 次則是花草茶提取液和中草藥萃取液。

此外, 通過對DPPH清除活性, 亦針對連續沖泡茶葉 後提取物來做比較, 以瞭解茶葉廢棄物回收再利用之可行 性。結果發現, 茶葉提取物不僅有利於產電刺激, 而且可 持續多次循環利用(圖3和表4)(例如綠茶於5個循環利用後 仍保有約 $47.24 \%$ 的清除活性, 烏龍茶循環再利用的清除 率為 $45.29 \%$ ) 。然而, 由於紅茶是完全發酵茶 (例如:滇 紅, 普洱茶), DPPH清除活性則顯著下降到 $10 \%$ (例如: C. yunnanica和C.assamica於第四次萃取後清除率更降至 $9.07 \%$ 和 $1.48 \%$ ）以下。換言之, 利用可食用植物和藥用 植物的回收廢棄物再利用之提取物用於可持續性之相關 生物能源開發應用在是具有技術可行性的。

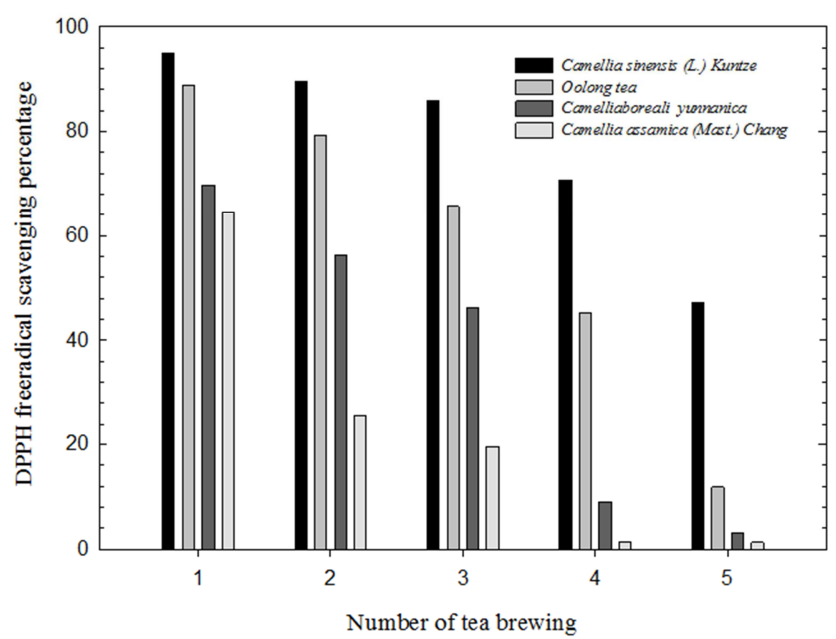

圖3 不同茶樹茶在不同茶葉沖泡時間後的抗氧化能力比較（100\%定義 為 $30 \mathrm{~min}$ 內完成 $1 \mathrm{mM} \mathrm{DPPH}$ 的處理）。

表4 不同普通茶經過不同次數萃取後剩餘抗氧化能力比較。

\begin{tabular}{llllll}
\hline \multicolumn{1}{|}{$\begin{array}{l}\text { \# of tea brewing } \\
\text { Camellia Tea }\end{array}$} & $\mathbf{1}^{\text {st }}$ & $\mathbf{2}^{\text {nd }}$ & $\mathbf{3}^{\text {rd }}$ & $\mathbf{4}^{\text {th }}$ & $\mathbf{5}^{\text {th }}$ \\
\hline Camellia sinensis (L.) Kuntze & 95.00 & 89.63 & 85.94 & 70.65 & 47.24 \\
Oolong tea & 88.71 & 79.18 & 65.72 & 45.29 & 11.79 \\
Camelliaboreali yunnanica & 69.75 & 48.79 & 33.21 & 9.07 & 3.12 \\
Camellia assamica (Mast.) & 64.52 & 25.54 & 19.55 & 1.48 & 1.31 \\
Chang & & &
\end{tabular}

事實上, Przygodzka等人[6]即提及抗氧化活性可能與 多酚和類黄酮的含量具有統計學相關性。由於先前研究假 設抗氧化劑和ES的兩種特性亦都是電化學相關的,多酚類 抗氧化物極可能顯示出顯著的能力來刺激MFC中的電子 轉移現象。因此, 實施MFC添加這些樣品提取物的功率密 度性能的比較, 有其必要性。試驗樣品的最大功率密度 (圖) 4) (單位: $\mathrm{mW} \mathrm{m}^{-2}$ ) 的排序為:

C. sinensis (L.) Kuntze (30.51) > Oolong tea $(21.10)>$ C. tinctoria $(19.06)>S$. aromaticum $(18.21)>C$. yunnanica $(17.31)>$ C. assamica (Mast.) Chang $(16.28) \cong C$. reticulate $(16.24)>$ L. japonica $(15.22)>$ B. perennis $(13.17)>$ Blank (11.40-12.56).

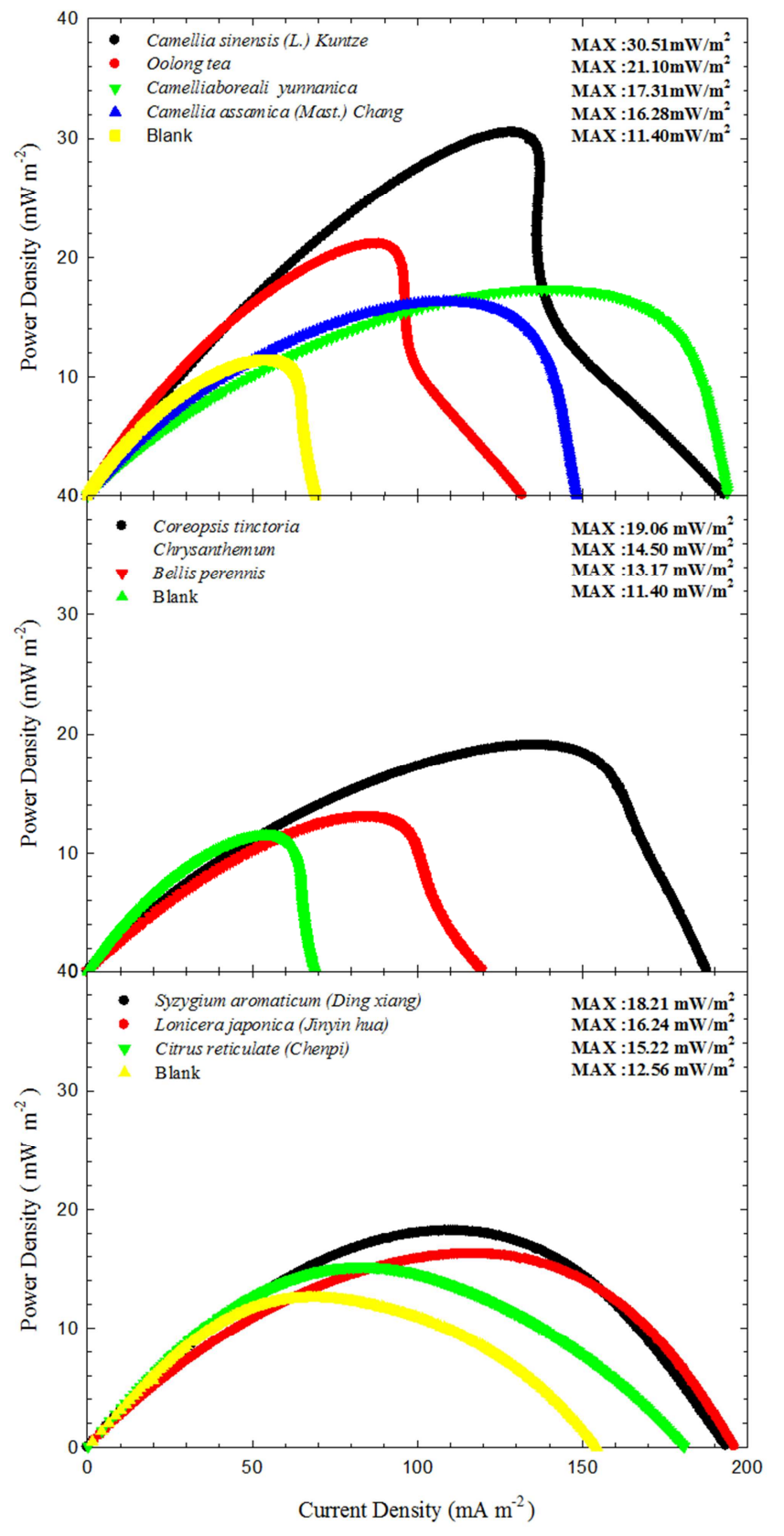

圖4 WLP72-Shewanella $s p$ 接種MFC的功率密度曲線比較 (A) 普通茶提 取物, (B) 花草茶提取物和 (C) 中草藥提取物。

先前文獻 $[18,19]$ 指出, 多酚類和黃酮類化合物的 CV 圖譜於合適的條件下, 可同時顯示出ES的還原和氧化電位 活性峰。於此, 功率密度結果顯示出富含多酚物質的植物 的抗氧化活性, 亦與能量刺激能力有直接相關。由自由基 清除能力的定量評估, 亦可推論出更有顯著ET條件者, 以 成為MFC之電子梭應用上, 來發揮其最大電子轉移生物效 能。

總之, 自總多酚含量與功率密度的刺激效率和DPPH 清除能力之間的關係(圖5)。再由量化數據顯示, 雖然仍可 能有協同或拮抗之交互作用來影響電子傳遞的混雜因素 存在, 但是與多酚含量仍如前所論具有相關性。可食用植 物和藥草的多酚含量可能可決定特定生物功能 (例如: 生 
物能源活性或可能的生物能量相關醫療治療能力) 的相關 電化學活性。

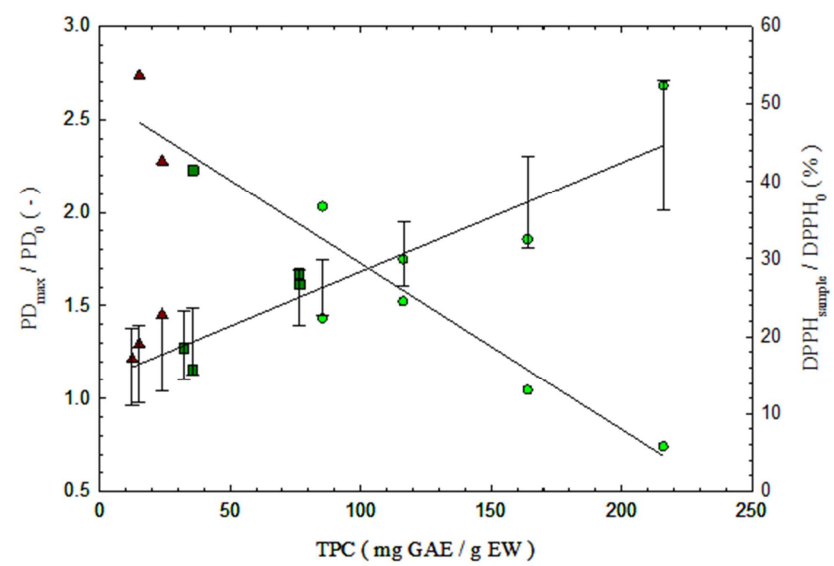

圖5 普通茶 $(0)$ ，花草茶 ( ) 和中草藥 $(\boldsymbol{)})$ 總多酚含量與功能密度增加 和DPPH殘留百分比的關係圖 $\left(\mathrm{PD}_{\max } / \mathrm{PD}_{0}\right)=1.0971+0.0058 \times \mathrm{TPC}\left(\mathrm{r}^{2}=\right.$ 0.8144 ), 其中 $\mathrm{PD}_{\max }$ 和 $\mathrm{PD}_{0}$ 分別表有和沒有無添加MFC的最大功率密度, 並且範圍條表示為 $95 \%$ 可信區間, 並且 $\left(\mathrm{DPPH}_{\text {sample }} / \mathrm{DPPH}_{0}\right)$ $=50.86-0.2144 \times \mathrm{TPC}\left(\mathrm{r}^{2}=0.9148\right)$ ，其中DPPH $\mathrm{Sample}_{\mathrm{k}}$ 表可用提取物清 除測試後DPPH殘餘量）。

\section{4. 研究展望及意義}

由 TPC, 抗氧化劑和電子穿梭能力之間的關係指出, 未發酵的普通茶 (即綠茶) 提取物的TPC含量比最佳中草 藥的TPC含量高了將近10倍。但是添加入MFC的功率密度 卻只提升大約3倍。推測可能有原因如下:（a）生物毒性: 普通茶提取物, 花草茶和中草藥對細菌具有生物毒性/抑 制效力 $[20,21]$, 會影響MFC的生物產電能力。因此, 增 加表現比預期的為少。（b）電子傳遞極限：儘管電子穿 梭能夠顯著刺激生物產電, 電極上固定化菌體量及碳布電 極特性等傳質因素仍限制了電子梭應用於MFC發電的表 現值。（c）抗氧化/電子梭轉換：重複的CV掃描結果亦表 明茶提取物的電活性物逐漸減弱。也就是說, 茶葉中含有 豐富的抗氧化物, 但電子梭化合物之含量比例可能實質上 相對較低。（d）CV與MFC環境差異：循環伏安法強化在 非生物電子供體和氧化還原反應的接受過程;然而, 生物 發電特性不是微生物必要的生理代謝功能, 因此其性能在 MFC中無法得到充分表達。（e）生物降解：茶葉提取物 中的某些成分不能單獨作為電子穿梭物使用, 亦可能被細 菌利用作為能源, 因此導致性能上低於預期所料。（f） 氧化還原可逆能力不足: 由於還原和氧化電位峰不對稱, 不可避免的存在著不平衡的電化學活性差異, 因此於氧化 還原電化學活性可能不能充分表現出可逆電子轉移 (亦 即氧化還原活性互變轉換上之不對等行為)。

上述皆可能是導致MFC結果不如預期的原因。破解其 中之奧祕, 對有效善加利用生物能源來做開發, 更具有經 濟可行性。根據先前研究 $[3,8]$ 電子梭具有可持續進行之氧 化還原反應以利於電子傳遞(圖6)作用, 而文獻[22]亦指出 $\mathrm{pH}$ 值上升會導致天然植物中常見的黃酮化合物抗氧化能 力上升,顯然電池中環境條件對電子梭活性影響甚鉅。另 外文獻 $[23,24]$ 亦指出茶葉的多酚經氧化酶氧化產生醌後 會受到游離之胺基酸影響, 一部分會經由 Strecker degradation變回多酚和醛, 但一部分則會進行 Michael reaction產生 $\mathrm{N}$-醌基衍生物, S-醌衍生物, 這亦可能使得電 子梭的能力降低, 皆有可能是使結果不如預期之原因。甚 至於相關中草藥藥效活性可能與電化學活性息息相關, 此 皆是後續有待深入討論之研究課題。<smiles>O=c1c(O)c(CCc2ccc(O)c(O)c2)oc2cc(O)cc(O)c12</smiles><smiles>[R]CC1([R])CC([R])C1[R]</smiles><smiles>CC(C)c1ccc(O)c(O)c1</smiles><smiles>CC(C)(C)c1ccc([O-])c(O)c1</smiles><smiles>[R]C([R])[C@@H]([R])[R]([R])([R])[R]</smiles><smiles>CC(C)C1=CC(=O)C(=O)C=C1</smiles>

圖6 黃酮類作為電子梭之反應機構。

\section{4. 結論}

富含多酚的食用植物和藥用植物極可能具有前瞻 開發的電化學能力, 以刺激MFC的生物產電。特別是, 普通茶提取物 (例如: 綠茶) 與花草茶和提神的藥草相 比, 更顯示出茶葉具有最高的生物電刺激能力。顯然, 電化學特性 (例如: 抗氧化劑和ES) 和總酚含量彼此息 息相關。又由於菊花茶類不含咖啡因且 TPC含量較高, 菊花茶提取物比其他非茶葉提取物更有前途開發。由於 茶葉提取物似乎比中草藥更適合藥用植物, 所以要於生 物能源和生物精煉應用之前提, 首先考慮植物草藥提取 物的生物毒性效能評價, 才能進入安全無虞之生物能量 之永續開發應用上。

\section{致謝}

台灣科技部對本計畫之經費補助支持（MOST 106-2221-E-197-020-MY3,106-2923-E-197-002-MY3,106-2 621-M-197-001, 105-2622-E-197-012-CC3）而部分結果已 在Bioresour Technol, 256 (2018) 95-101發表亦一併致上誠 摰感謝之意。

\section{參考文獻}

[1] Chen BY, Ma CM, Han K, Yueh PL, Qin LJ, Hsueh CC. Influence of textile dye and decolorized metabolites on microbial fuel cell-assisted bioremediation. Bioresource technology. 2016;200:1033-8.

[2] Xu B, Chen BY, Hsueh CC, Qin LJ, Chang CT. Deciphering characteristics of bicyclic aromatics--mediators for reductive decolorization and bioelectricity generation. Bioresource technology. 2014;163:280-6. 
[3] Qin L-J, Han K, Yueh P-L, Hsueh C-C, Chen B-Y. Interactive influences of decolorized metabolites on electron-transfer characteristics of microbial fuel cells. Biochemical Engineering Journal. 2016;109:297-304.

[4] Chen B-Y, Ma C-M, Liao J-H, Hsu A-W, Tsai P-W, Wu C-C, et al. Feasibility study on biostimulation of electron transfer characteristics by edible herbs-extracts. Journal of the Taiwan Institute of Chemical Engineers. 2017.

[5] Chen B-Y, Hsu A-W, Wu C-C, Hsueh C-C. Feasibility study on biostimulation of dye decolorization and bioelectricity generation by using decolorized metabolites of edible flora-extracts. Journal of the Taiwan Institute of Chemical Engineers. 2017.

[6] Przygodzka M, Zielińska D, Ciesarová Z, Kukurová K, Zieliński H. Comparison of methods for evaluation of the antioxidant capacity and phenolic compounds in common spices. LWT - Food Science and Technology. 2014;58(2):321-6.

[7] Shang X, Pan H, Li M, Miao X, Ding H. Lonicera japonica Thunb.: ethnopharmacology, phytochemistry and pharmacology of an important traditional Chinese medicine. J Ethnopharmacol. 2011;138(1):1-21.

[8] Chen B-Y, Hsueh C-C. Deciphering Electron Shuttles for Bioremediation and Beyond. American Journal of Chemical Engineering. 2016;4(5):114.

[9] Oliveira GK, Tormin TF, Sousa RM, de Oliveira A, de Morais SA, Richter EM, et al. Batch-injection analysis with amperometric detection of the DPPH radical for evaluation of antioxidant capacity. Food Chem. 2016;192:691-7.

[10] Sharma Y, Li B. The variation of power generation with organic substrates in single-chamber microbial fuel cells (SCMFCs). Bioresource technology. 2010;101(6):1844-50.

[11] Logan BE, Regan JM. Electricity-producing bacterial communities in microbial fuel cells. Trends in microbiology. 2006;14(12):512-8.

[12] Chen G-L, Chen S-G, Xiao Y, Fu N-L. Antioxidant capacities and total phenolic contents of 30 flowers. Industrial Crops and Products. 2018;111:430-45.

[13] Pires TCSP, Dias MI, Barros L, Calhelha RC, Alves MJ, Oliveira MBPP, et al. Edible flowers as sources of phenolic compounds with bioactive potential. Food Research International. 2018;105:580-8.
[14] Guo L, Zhang W, Li S, Ho C-T. Chemical and nutraceutical properties of Coreopsis tinctoria. Journal of Functional Foods. 2015;13:11-20.

[15] Jin L, Li X-B, Tian D-Q, Fang X-P, Yu Y-M, Zhu H-Q, et al. Antioxidant properties and color parameters of herbal teas in China. Industrial Crops and Products. 2016;87:198-209.

[16] Jeszka-Skowron M, Krawczyk M, Zgoła-Grześkowiak A. Determination of antioxidant activity, rutin, quercetin, phenolic acids and trace elements in tea infusions: Influence of citric acid addition on extraction of metals. Journal of Food Composition and Analysis. 2015;40:70-7.

[17] Chen BY, Xu B, Qin LJ, Lan JC, Hsueh CC. Exploring redox-mediating characteristics of textile dye-bearing microbial fuel cells: thionin and malachite green. Bioresource technology. 2014;169:277-83.

[18] Ferreira RdQ, Greco SJ, Delarmelina M, Weber KC. Electrochemical quantification of the structure/antioxidant activity relationship of flavonoids. Electrochimica Acta. 2015;163:161-6.

[19] Masek A, Zaborski M, Chrzescijanska E. Electrooxidation of flavonoids at platinum electrode studied by cyclic voltammetry. Food Chem. 2011;127(2):699-704.

[20] Mirpour M, Gholizadeh Siahmazgi Z, Sharifi Kiasaraie M. Antibacterial activity of clove, gall nut methanolic and ethanolic extracts on Streptococcus mutans PTCC 1683 and Streptococcus salivarius PTCC 1448. J Oral Biol Craniofac Res. 2015;5(1):7-10.

[21] Guo J, Wang A, Yang K, Ding H, Hu Y, Yang Y, et al. Isolation, characterization and antimicrobial activities of polyacetylene glycosides from Coreopsis tinctoria Nutt. Phytochemistry. 2017;136:65-9.

[22] Lema'Nska K, Szymusiak H, Tyrakowska BZ, Zieli'R, Soffers EMF, Rietjens IMCM. The Influence of $\mathrm{pH}$ on Antioxidant Properties and the Mechanism of Antioxidant Action of Hydroxyflavones. Free Radical Biology \& Medicine. 2001;31(7):869-81.

[23] Bittner S. When quinones meet amino acids: chemical, physical and biological consequences. Amino Acids. 2006;30(3):205-24.

[24] Oliveira CM, Santos SA, Silvestre AJ, Barros AS, Ferreira AC, Silva AM. Quinones as Strecker degradation reagents in wine oxidation processes. Food Chem. 2017;228:618-24. 